\section{Epiploic appendages' inflammation: appendagitis. Report of two cases and literature overview}

\author{
Aldo Di Blasi, ${ }^{1}$ Luigi Zulli, ${ }^{2}$ \\ Antonio Viscomi, ${ }^{1}$ Augusto Tricerri \\ 'Department of Clinical Radiology; \\ 2Department of Emergency Medicine, \\ P.O. San Filippo Neri, ASL Roma1, Rome, \\ Italy
}

\begin{abstract}
Epiploic Appendagitis (EA) is an uncommon, benign, self-limiting inflammatory process of the epiploic appendices. Other, older terms for the process include appendicitis epiploica and appendagitis, but these terms are used less now in order to avoid confusion with acute appendicitis. Epiploic appendices are small, fat-filled sacs or finger-like projections along the surface of the lower colon and rectum. They may become acutely inflamed as a result of torsion (twisting) or venous thrombosis. The inflammation causes pain, often described as sharp or stabbing, located on the left, right, or central regions of the abdomen. There is sometimes nausea and vomiting. The symptoms may mimic those of acute appendicitis, diverticulitis, or cholecystitis. Initial lab studies are usually normal. EA is usually diagnosed incidentally on CT scan which is performed to exclude more serious conditions. Epiploic appendagitis usually does not require surgical intervention. It is self-limiting, the symptoms can be treated with analgesics and subsides in about a week.
\end{abstract}

\section{Introduction}

Acute abdominal pain (AAP) is the most common surgical emergency, one of the most common symptom for referral to an emergency department and the most common cause for non-trauma-related hospital admissions; ${ }^{1}$ it accounts for about $8 \%$ of the total ED visits as chief complaint at entry in the United States. ${ }^{2}$

In a recent study AAP appeared to be one of the most frequent causes of referral to the ED of a large university hospital in Italy with an observed prevalence of $9.1 \% 0^{3}$ and 5.76 in a different academic hospital in a similar study. ${ }^{4}$

In our experience, in a middle size hospital with a I level emergency department,
AAP, as main problem for the referral to the emergency department, accounts for $4.7 \%$ of all accesses in 2011 and $4.6 \%$ in 2015 .

The incidence of undefined diagnosis among the patients who reported acute abdominal pain as their chief complaint at admission was $47.3 \%$ and $34.8 \%$ respectively in two studies. ${ }^{3,4}$

Appendagitis is a relatively rare cause of AAP that can be confused with other causes, and misdiagnosed as acute appendicitis or colon diverticulitis. Traditionally ranked among the rare causes of acute abdominal pain, as a result of the widespread use of CT in emergency-urgency, cases of appendagitis are reported more and more frequently in the literature.

First reported in 1959 by T Case, ${ }^{5}$ epiploic appendagitis remain an unusual finding often neglected in the differential diagnosis of acute abdominal pain as reported in a study by van Breda Vriesman et al., ${ }^{6}$ where such pathology was included in the clinical differential diagnosis in only two of 49 patients of acute abdomen.

Epiploic appendagitis (torsion) accounts for $1.3 \%$ of patients presenting with abdominal pain and constitutes 8.8 cases per million a year in the general population. $^{7}$

Golash et al. ${ }^{8}$ reported a series of 1,320 cases of acute abdominal pain among which only eight cases were due to acute epiploic appendagitis.

Anatomically, the epiploic appendages are serous adipose tissue filled pockets, visible on the serosal colon surface, which are joined by a vascular pedicle. They are 50100 small finger-like structures, located between the cecum and sigmoid colon, length from 0.5 to $5 \mathrm{~cm}$; those close to the sigmoid colon are wider. Approximately $57 \%$ of these are located in the sigmoid colon and $26 \%$ in the cecum. Epiploic appendages are not found into the rectum. ${ }^{9}$

Epiploic appendages are arranged in two rows: a row medial to the tapeworm free, the other side close to the omental tenia. More than half of them are located in the descending colon and sigmoid, which explains why the majority of pathological cases are in the lower left quadrant.

Various hypotheses have been suggested about their function: some authors believe that these structures may have a function as an anti-inflammatory or bacteriostatic omentum in miniature, others suggest a function of cushion in the peristalsis of the colon, while others think it is a reserve for the local club when the colon and blood vessels contract.

The primitive epiploic appendagitis is caused by the inflammation, torsion or ischemia of an epiploic appendage.
Correspondence: Augusto Tricerri, P.O San Filippo Neri, ASL Roma1, via Martinotti 20 00135, Rome, Italy.

Tel.: 06.3306.2276

E-mail: Augusto.Tricerri@aslroma1.it

Key words: Appendigitis, acute abdominal pain, emergency department.

Contributions: $\mathrm{ADB}, \mathrm{AV}$ were involved in the radiologic diagnosis and follow-up; AT, LZ reviewed the clinical records and the literature.

Conflict of interest: the authors declare no potential conflict of interest.

Received for publication: 1 May 2017.

Revision received: 22 October 2017.

Accepted for publication: 26 October 2017.

This work is licensed under a Creative Commons Attribution 4.0 License (by-nc 4.0).

CC Copyright A. Di Blasi et al., 2017

Licensee PAGEPress, Italy

Emergency Care Journal 2017; 13:6775

doi:10.4081/ecj.2017.6775

Epiploic appendages are highly mobile structures, so the main pathological mechanism of acute inflammation is the appendix torsion. The torsion occurs on the long axis and is followed by various events that lead to ischaemia; the venous component is the first to be hit as these structures are supplied by one or two arterioles and a single venule. Other mechansms are represented by spontaneous venous thrombosis, lymphoid hyperplasia, bacterial invasion.

The inflammation can also be secondary to other diseases such as appendicitis, diverticulitis, Crohn's disease, cholecystitis, pancreatitis, salpingitis. Complications such as adhesions, abscess, bowel obstruction are very rare.

Appendagitis sometimes are associated with obesity and hernias, it has been hypothesized that it may result from intense and exaggerated exercise, and temporary dehydration.

Clinical evidences show that this disease is more common in the fourth to fifth decade of life; it is rarely seen in patients younger than 19 years old and is almost unknown in children, as only a few case reports of epiploic appendagitis involving caecum in children have been published in literature. ${ }^{10,11}$ Searching the pubmed database in 2017, for appendagitis resulted in 62 occurrences for the last five years, of these only 4 reports concerned pediatric patients.

Contrasting data about the males/female ratio are reported in literature: a recent 
study reported 8 females out of 12 patients $(66 \%)$ with an age range between 36 and 65 years ${ }^{12}$ while an older one reported a $82 \%$ of males with a median age of 44.7 years ${ }^{13}$ so that it should be considered not to have sex predilection. ${ }^{14}$

In a case series of 58 patients with EA, $48 \%$ of cases occurred in the sigmoid colon, $28 \%$ in the descending colon, $7 \%$ in the transverse colon, and $17 \%$ in the ascending colon. ${ }^{15}$

Clinical presentation of acute appendagitis is usually characterized by the abrupt onset of acute, well-localized, nonmigratory abdominal pain, often in the lower abdominal quadrants, and frequently it worsens with movement. ${ }^{9}$ The patient usually is afebrile without nausea, vomiting, anorexia, or change in bowel function. ${ }^{16,17}$ On physical examination the patient presents with localized tenderness and possible guarding. Usually vital signs and laboratory values are within normal limits, but mild leukocytosis and slight elevation of $\mathrm{C}$-reactive protein have been reported in some cases as well as piuria in $5 \%$ of one series ${ }^{13,16,17}$ (Table 1 ).

The diagnostic hypothesis based only on clinical presentation, often does not allow the recognition of this disease.

\section{Case Reports}

\section{Case \#1}

A 44-year-old male without any past medical history, presented to the ED complaining for a left lower quadrant pain, which had started 18 hours before admission with a severity of six out of 10 , nausea, and low grade fever without vomiting, constipation or diarrhea. Abdominal examination showed focal abdominal tenderness without rebound tenderness and normal peristalsis. The only laboratory values of significance were a slightly elevated Creactive peptide (CRP) of $4.5 \mathrm{mg} / \mathrm{dL}(<0.8$ $\mathrm{mg} / \mathrm{dL}$ ) and a leukocyte count of 14,480/ul. Neither the Abdominal X ray nor the ultrasound scan showed any abnormal finding, therefore an abdominal contrast enhanced computed tomography (CT) was performed with the report of the presence of hyperdensity of left pericolic adipose tissue with thickening of the adjacent intestinal wall (Figure 1). The described finding were consistent with an inflammatory process of the epiploic appendage. Ceftriaxone $2 \mathrm{gr} / \mathrm{die}$ IV and metronidazole $500 \mathrm{mg} / \mathrm{tid}$ were administered starting in the ED and continued for 5 days after admission to the Emergency medicine ward and within three days the symptoms resolved.

\section{Case \#2}

A 47-year-old Caucasian woman presented with a history of episodes of abdominal pain lasting from about 2 months that in the last 2 days progressively worsened becoming subcontinuous and that did not recede after a hyoscine butylbromide $10 \mathrm{mg}$ tablet. Rebound tenderness was noted in the left iliac fossa without guarding. Bowel sounds were present. On a pain scale of 1 to 10, she rated the pain 7. She denied any associated chills, fever, nausea, vomiting, or skin rash. In the past history there was an acute pancreatitis with gallbladder stones requiring cholecystectomy.

Laboratory tests, including leucocyte count and CRP were in normal ranges. Abdominal plain $\mathrm{X}$ rays and ultrasound scan were performed without any abnormal finding.

The patient underwent a CT scan with the finding of focal wall thickening of the descending colon with adipose tissue alterations in the context of which is detected a hypodense area with hyperdense peripheral rim and contrast enhancement (Figure 2). According to the suggestion of the gastoenterology specialist the patient was treated with ciprofloxacin $200 \mathrm{mg}$ iv bid and admitted to the emergency medicine ward. After 5 days she was discharged. After 3 years she presented again in the ED for acute abdominal pain and underwent a new CT scan without evidence of any pathologic finding.

\section{Diagnostic imaging of appendagitis}

Because of the nonspecific signs and symptoms of this disease, in the past the diagnosis of appendagitis was often the unexpected finding of a laparotomic exploration. The suspected diagnosis of appendagitis was usually placed in patients operated on for appendicitis with pain in the right lower quadrant abdominal or in patients with symptoms suggestive of diverticulitis, in which, however, previous diagnostic tests had excluded this hypothesis.

This pathology is much difficult to distinguish in ultrasound. Despite its superficial location under the abdominal wall, it does not distinguish itself clearly from adjacent tissues. An indicating sign is localized pain reported by patients or evoked with the use of a transducer. At this site, one can see a slightly hyperechoic structure, usually of ovoid shape and sometimes surrounded with a halo. It does not present vascularity or undergo deformation upon compression. In some cases, a central hypoechoic area with a blurred outline can be spotted. Such a lesion sometimes adheres to the parietal peritoneum during deep inspiration. It usually slightly deviates externally and lies on

Table 1. Clinical and radiologic findings in acute appendagitis.

\section{Clinical features}

Acute abdominal pain, with abrupt onset,

often in the lower abdominal quadrants

Age: 4th-5th decade of life

No fever

No changes in bowel function

Laboratory values usually within normal limits
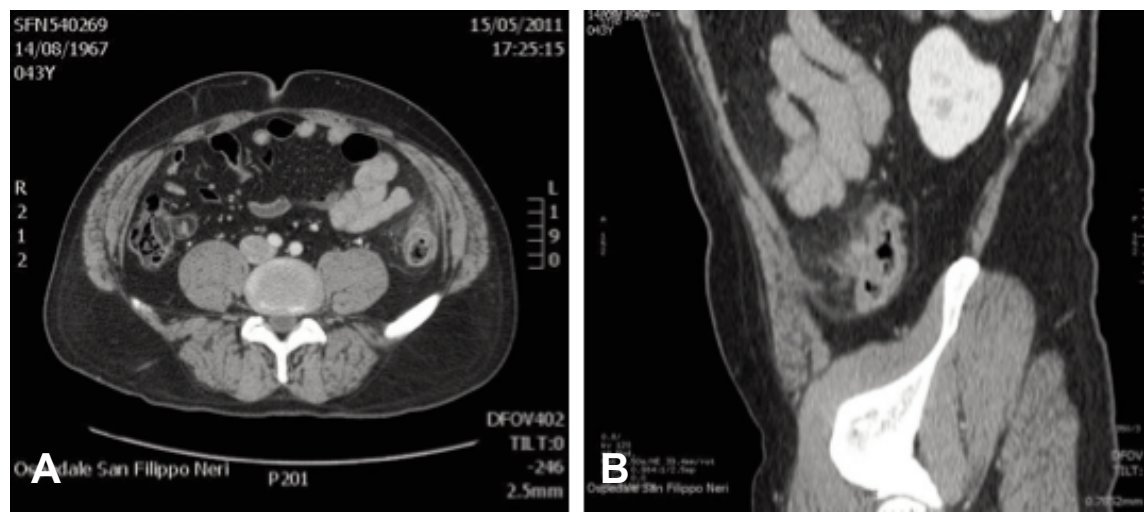

Figure 1. Presence of hyperdensity of left pericolic adipose tissue with thickening of the adjacent intestinal wall. 
the intestinal wall that is not thickened. ${ }^{18-21}$

Elastography and contrast-enhanced ultrasound can be helpful in the diagnosis. ${ }^{22,23}$ Lesions located deeper in the pelvis minor are usually imaged by transrectal ultrasound. ${ }^{24}$ There are cases in which omental infarction is indistinguishable.

Moreover, primary epiploic appendagitis may mimic peritoneal implants of cancers, particularly ovarian carcinoma. ${ }^{21}$

The widespread availability of CT scan in the emergency department has definitely improved the diagnosis of acute abdominal pain superseding plain abdominal and chest films.

The most characteristic finding is represented by an oval lesion with a diameter less than $5 \mathrm{~cm}$ (mean diameter $1.5 \mathrm{~cm}-3.5$ ) and density values equal to those of the fat, adjacent to the anterior wall of the colon, surrounded by alterations of inflammatory type. ${ }^{25}$

Sometimes it is possible to appreciate a thickening of the parietal peritoneum and peritoneal dissemination secondary to inflammation; the colon wall may appear thickened too, but most of the times is normal. Often at the center of the lesion is observed an hyperdense central point due to venous thrombosis, whose presence confirms the diagnosis, but its absence does not exclude it.

The most common sites of appendagitis detected by $\mathrm{CT}$ are, in descending order, the areas near the sigmoid colon, the descending colon, the right colon (Table 1).

Even if the symptoms is achieved in about two weeks, in most patients the CT findings persist longer, so within 6 months from the onset of clinical manifestations, images can be very variable: from the absence of any modification, to a decreased size of the lesions and residual alterations in the density of the soft tissues. In general, the
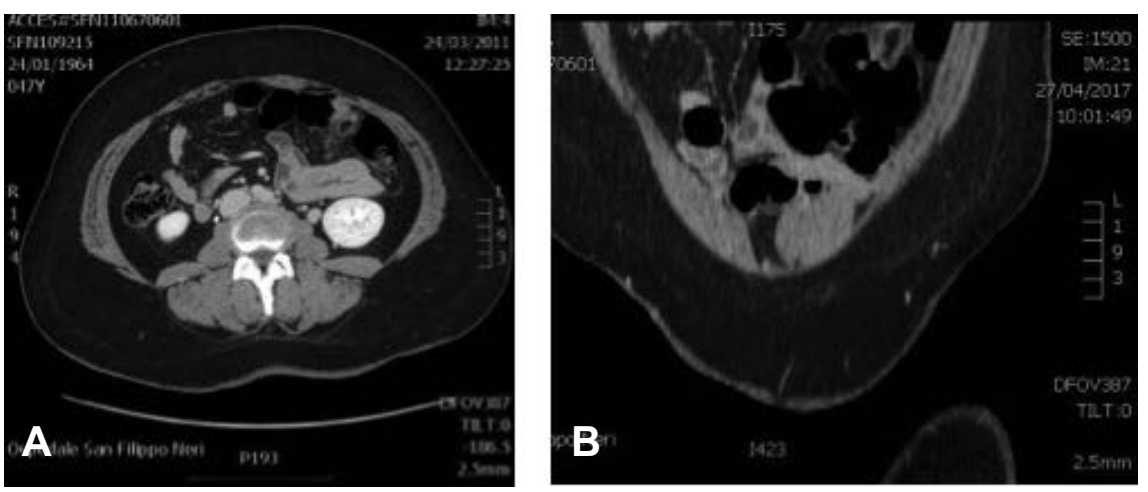

Figure 2. Focal wall thickening of the descending colon with adipose tissue alterations in the context of which is detected a hypodense area with hyperdense peripheral rim and contrast enhancement. resolution takes place in approximately six months after the onset.

In the differential CT diagnosis omental infarction, acute inflammation such as diverticulitis, sclerosing mesenteritis, primary or metastatic mesocolon tumors should be considered. ${ }^{26}$

In the clinical course and subsequent radiological control at a distance of at least three to six months, it is rare to find complications if they exist, are represented by adhesions, peritonitis, abscess, possible sub-occlusion or bowel obstruction.

\section{Conclusions}

AAP of non-traumatic origin is one of the more frequent complaints leading people to EDs, the analysis of our data shows a stable rate of access for such a symptom in the last 5 years, concurrent with data from other Italian hospitals.

The management of abdominal pain is challenging decision-making process that unfortunately leads to a non specific diagnosis in up to $40 \%$ of patients. sophisticated imaging techniques has not generated a substantial reduction of the admission rate. ${ }^{27}$

In our experience, comparing data from a 2011 and a 2015 survey, we found a minimal difference in the wide use of plain abdominal X-ray, despite the evidence of scarce diagnostic performance $(50.35 \%$ vs 48.56), while the prescription of a CT scan increased from $18 \%$ to $30 \%$, and ultrasound diagnostic was prescribed in up to $95 \%$ of patients.

Among the rare causes of acute abdomen appendagitis plays a consistent role although in a reported series of 1,320

\section{B}

[Emergency Care Journal 2017; 13:6775]
The availability and widespread use of cases of acute abdominal pain, only eight cases were due to PEA. ${ }^{28}$

In the context of time sparing strategies, reduction of patient's time spent in the ED and, on the other hand, reduction of admission rates and decrease of in hospital length of stay, a sharper differential diagnosis and the recognition of self-limiting disease, not of surgical interest, can gain a relevant weight for optimal patients management and must avoid surgical inappropriate treatments.

Appendagitis can confuse clinicians because of its rarity and lack of pathognomonic clinical signs. Applying guidelines, and using the most effective diagnostic tools, can lead to resource optimization and improve the diagnosis of ever rare conditions. Widespread diffusion of early CT scan evaluation allows to distinguish PEA from other conditions with similar clinical manifestations but with a stronger surgical commitment. In our experience the antibiotic and anti-inflammatory treatment allows a full recovery of the patients leaving any sign in a subsequent $\mathrm{CT}$ control.

The awareness of this disease between the emergency physicians can reduce the non-specific diagnosis of AAPP and can contribute to continuous quality improvement in the ED.

\section{References}

1. Macaluso CR, McNamara RM. Evaluation and management of acute abdominal pain in the emergency department. Int J Gen Med 2012;5:78997.

2. National Center for Health Statistics (NCHS). National Hospital Ambulatory Medical Care Survey: 2010 Emergency Department Summary Table. Centers for Disease Control and Prevention. Available from: http://www.cdc.gov/nchs/data/ahcd/nha mcs_emergency/2010_ed_web_tables.p df

3. Caporale N, Morselli-Labate AM, Nardi $\mathrm{E}$, et al. Acute abdominal pain in the emergency department of a university hospital in Italy. Unit Eur Gastroenterol J 2016;4:297-304.

4. Cervellin G, Mora R, Ticinesi A, et al. Epidemiology and outcomes of acute abdominal pain in a large urban Emergency Department: retrospective analysis of 5,340 cases. Ann Trans1 Med 2016;4:362.

5. Case TC. Acute epiploic appendagitis. Surgery 1959;46:1047-53.

6. van Breda Vriesman AC, de Mol van 
Otterloo JC, Puylaert JB. Appendagitis epiploica: een onderbelichte zelflimiterende acute buikaandoening [Epiploic appendagitis: an underestimated self limiting acute abdominal condition]. Ned Tijdschr Geneeskd 2003;147:1113-8.

7. de Brito P, Gomez MA, Besson M, et al. Frequency and epidemiology of primary epiploic appendagitis on CT in adult with abdominal pain. J Radiol 2008;89:235-43.

8. Golash V, Willson PD. Early laparoscopy as a routine procedure in the management of acute abdominal pain: a review of 1,320 patients. Surg Endosc 2005;19:882-5.

9. Sand M, Gelos M, Bechara FG, et al. Epiploic appendagitis-clinical characteristics of an uncommon surgical diagnosis. BMC Surg 2007; 7:11.

10. Christianakis E, Paschalidis N, Filippou $\mathrm{G}$, et al. Cecal epiploica appendix torsion in a female child mimicking acute appendicitis: a case report. Cases J 2009;2:8023.

11. Gupta V, Kumar S. Appendicitis epiploicae: an unusual cause of acute abdomen in children. J Indian Assoc Pediatr Surg 2008;13:83-4.

12. Nadida D, Amal A, Ines M, et al. Acute epiploic appendagitis: radiologic and clinical features of 12 patients. Int $\mathrm{J}$ Surg Case Rep 2016;28:219-22.
13. Freitas GP, Borges AA, Mendonça R, et al. Apendagite epiplóica: aspectos clínicos e radiológicos. Arq Gastroenterol 2008;45:163-5.

14. Fieber SS, Forman J. Appendices epiploicae: clinical and pathological considerations; report of three cases and statistical analysis on one hundred five cases. AMA Arch Surg 1953;66:329-38.

15. Patel NB, Wenzke DR. Evaluating the patient with right lower quadrant pain. Radiol Clin North Am 2015;53:115970.

16. Schnedl WJ, Krause R, WallnerLiebmann SJ, et al. Primary epiploic appendagitis and successful outpatient management. Med Sci Monit 2012;18: CS48-51.

17. Shrestha B, Hampton J. Recurrent epiploic appendagitis and peritoneal dialysis: a case report and literature review. World J Nephrol 2014;3:114-7.

18. Coulier B. Contribution of US and CT for diagnosis of intraperitoneal focal fat infarction (IFFI): a pictorial review. JBR-BTR 2010;93:171-85.

19. Kamaya A, Federle MP, Desser TS. Imaging manifestations of abdominal fat necrosis and its mimics. Radiographics 2011;31:2021-34.

20. Almeida AT, Melão L, Viamonte B, et al. Epiploic appendagitis: an entity frequently unknown to clinician-diagnostic imaging, pitfalls, and look-alikes.
AJR Am J Roentgenol 2009;193:124351.

21. Smereczyński A, Kołaczyk K, Bernatowicz E. Intra-abdominal fat. Part II: Non-cancerous lesions of the adipose tissue localized beyond organs. J Ultrason 2016;16:32-43.

22. Görg C, Egbring J, Bert T. Contrastenhaced ultrasound of epiploic appendagitis. Ultraschall Med 2009;30: 163-7.

23. Menozzi G, Maccabruni V, Zanichelli M, Massari M. Contrast-enhanced ultrasound appearance of primary epiploic appendagitis. J Ultrasound 2014;17:756.

24. Chou YH, Chen JD, Tiu CM, et al. Epiploic appendagitis of the rectosigmoid junction: demonstration with transrectal sonography. J Clin Ultrasound 2006;34:450-3.

25. Singh AK, Gervais DA, Hahn PF, et al. CT of acute appendagitis. Am J Roentgenol 2004;183:303-1307.

26. Kamaya A, Federle MP, Desser TS Imaging manifestations of abdominal fat necrosis and its mimics. Radiographics 2011;31:2021-34.

27. Hastings RS, Powers RD. Abdominal pain in the ED: a 35year retrospective. Am J Emerg Med 2011;29:711-6.

28. Malik KA. Torsion of an epiploic appendix pretending as acute appendicitis. Oman Med J 2010;25:225-6. 